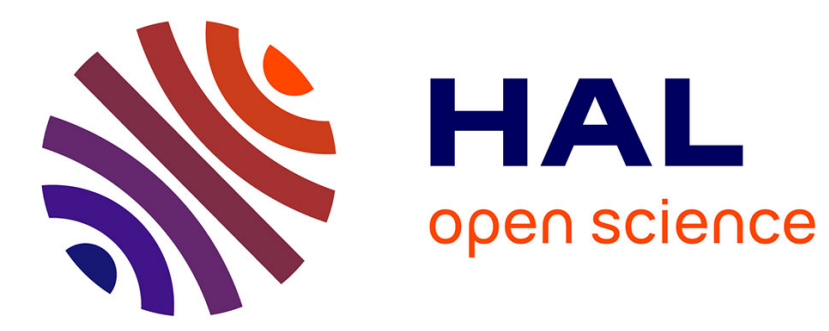

\title{
Wood peeling process monitoring: a comparison of signal processing methods to estimate veneer average lathe check frequency
}

Louis Denaud, Laurent Bleron, Florent Eyma, Rémy Marchal

\section{To cite this version:}

Louis Denaud, Laurent Bleron, Florent Eyma, Rémy Marchal. Wood peeling process monitoring: a comparison of signal processing methods to estimate veneer average lathe check frequency. European Journal of Wood and Wood Products, 2012, 70 (1-3), pp.253-261. hal-00870601

\section{HAL Id: hal-00870601 https://hal.science/hal-00870601}

Submitted on 24 Oct 2013

HAL is a multi-disciplinary open access archive for the deposit and dissemination of scientific research documents, whether they are published or not. The documents may come from teaching and research institutions in France or abroad, or from public or private research centers.
L'archive ouverte pluridisciplinaire HAL, est destinée au dépôt et à la diffusion de documents scientifiques de niveau recherche, publiés ou non, émanant des établissements d'enseignement et de recherche français ou étrangers, des laboratoires publics ou privés. 


\title{
Wood peeling process monitoring: a comparison of signal processing methods to estimate veneer average lathe check frequency
}

\author{
Louis Etienne Denaud · Laurent Bléron • \\ Florent Eyma · Rémy Marchal
}

\begin{abstract}
Experienced peeling operators are able to adjust the settings of their device by hearing the sound coming from the process. Based on this idea, a research program was undertaken to evaluate the possibility of using acoustic or vibration measurements supplying a support decision system to assist untrained operators.

The present paper deals with lathe check phenomenon which is one of the most critical defects of veneer (leading to handling difficulties, excess of glue consumption, poor veneer surface quality, etc.). Several signal processing techniques giving a spectral representation of sensors measurements are compared. Finally, an original procedure based on Power Spectral Density ratio is proposed to measure the average lathe check frequency of the veneer during the process.

\section{Prozessüberwachung beim Holzschälen: Vergleich verschiedener Verfahren zur Bestimmung der mittleren Rissfrequenz bei Schälfurnieren}

Zusammenfassung Erfahrene Schälmaschinenführer können die Maschineneinstellungen nach Gehör vornehmen. Davon ausgehend wurde ein Forschungsprogramm initiiert, in welchem untersucht werden soll, ob Schall- oder Schwingungsmessungen als Entscheidungshilfe für unerfahrene Arbeiter genutzt werden können.

L.E. Denaud $(\bowtie) \cdot$ L. Bléron · R. Marchal

LaBoMaP, Arts et Metiers-ParisTech, Rue Porte de Paris, 71250

Cluny, France

e-mail: louis.denaud@ensam.eu

\section{F. Eyma}

Institut Clément Ader, University Paul Sabatier-IUT Tarbes,

Département Génie Mécanique et Productique, 1 rue

Lautréamont, BP 1624, 65016 Tarbes, France
Die vorliegende Studie beschäftigt sich mit Schälrissen, einem der kritischsten Mängel bei Furnieren, die zu Schwierigkeiten bei der Bearbeitung, wie z. B. übermäßigem Klebstoffverbrauch oder schlechter Qualität der Furnieroberflächen führen können. Verschiedene Signalverarbeitungsverfahren, die eine spektrale Darstellung der Sensormessungen liefern, werden verglichen. Abschließend wird ein neues Verfahren zur Messung der mittleren Rissfrequenz bei Furnieren vorgeschlagen, das auf dem spektralen Leistungsdichteverhältnis (PSD) basiert.

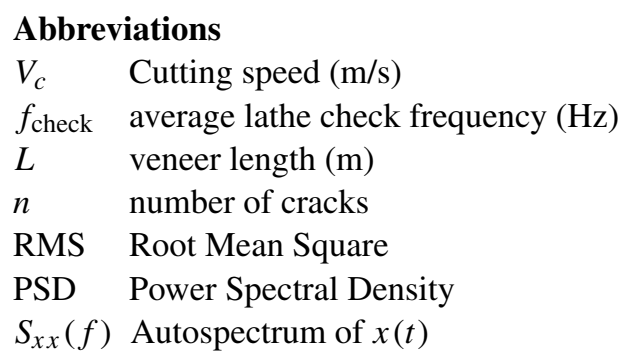

\section{Introduction}

Peeling is a wood process largely used for plywood, LVL (Laminated Veneer Lumber) and packaging production. Suffering from strong competition of other products such as plastic packaging or OSB panels (Oriented Strand Board) as well as difficult access to the required forestry resource, veneer production has to be improved in order to remain competitive. One of the most promising ways to cope with this challenge is to develop an on-line control system of the lathe or, at least, a support decision system for operators.

Several technologies were tested to reach this objective. The first one uses forces measurement. It requires a specific design of the lathe. Although the resulting additional 


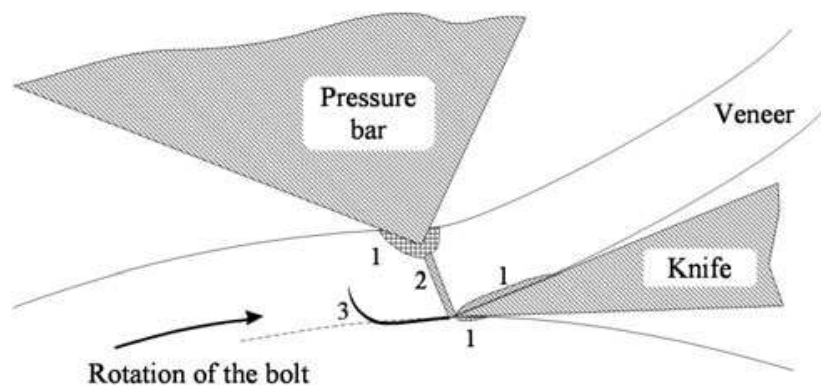

1 : High compression and friction zone

2 : Main shearing plane

3 : Macroscopic crack

Fig. 1 Main mechanical phenomenon during the peeling process (inspired by Thibaut and Beauchêne 2004)

Abb. 1 Mechanische Gegebenheiten beim Schälprozess (nach Thibaut and Beauchêne 2004)

cost is not suitable for industrial constraints, this is an efficient method to improve cutting mechanism knowledge. Thibaut and Beauchêne (2004) propose a simplistic cutting force model able to describe chip formation and lathe check generation. Good quality veneers are achieved by shearing in a plane almost perpendicular to the rake face of the knife (Fig. 1). Beyond a particular thickness, essentially depending on wood density and wood temperature, the energy required to produce the veneer becomes lower by splitting than by shearing. Indeed, the cutting geometry generates a traction stress field which favours check opening (see Fig. 1). It must be noticed that lathe check occurrence has been numerously studied for its consequences both on veneer quality and mechanical panel properties (Ohya et al. 1989; DeVallance et al. 2007). According to extensive observations (Leney 1960a, 1960b; Lutz 1974 and Thibaut 1988), this phenomenon is almost periodic for homogeneous wood species. To limit splitting occurrence and growth, an antagonistic compression stress field is applied by a pressure bar as presented in Figs. 1,2 and 3. However, the pressure bar could interfere with the cutting mechanism by producing a periodic variation of the veneer thickness. This thickness variation could be equally penalising in regard to both veneer and by-products quality. According to Thibaut (1988), the force applied on the rake face is a very good indicator for veneer thickness and lathe check occurrence at the same time. This approach is nevertheless limited to laboratory applications.

Marchal et al. (2000) underlined the fact that experienced peelers are able to adapt parameter settings only by hearing the sound coming from the process. It means that there must be acoustic or vibratory signatures of the veneer defects. Up to now, few works have been realised with acoustic or vibratory sensors as sources of data for wood machining. The most promising one mentioned by Marchal et al. (2009) uses approaches inspired by a vast metal cutting literature.

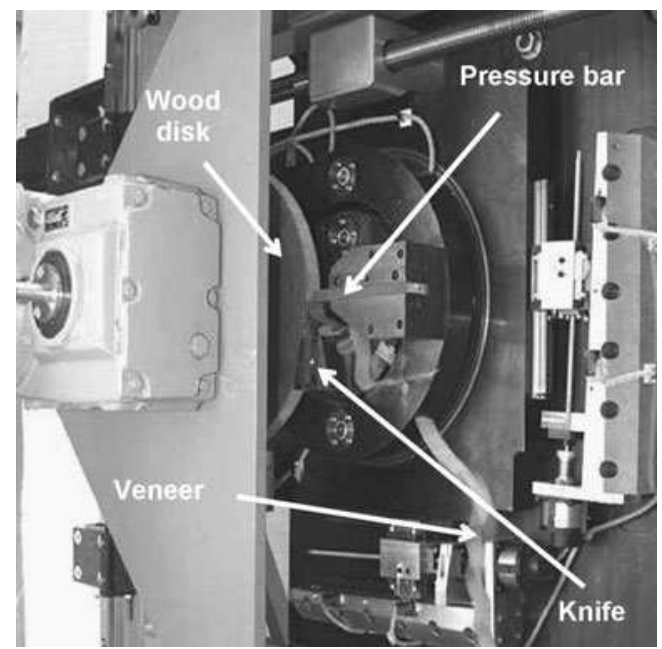

Fig. 2 Microlathe

Abb. 2 Laborschälmaschine

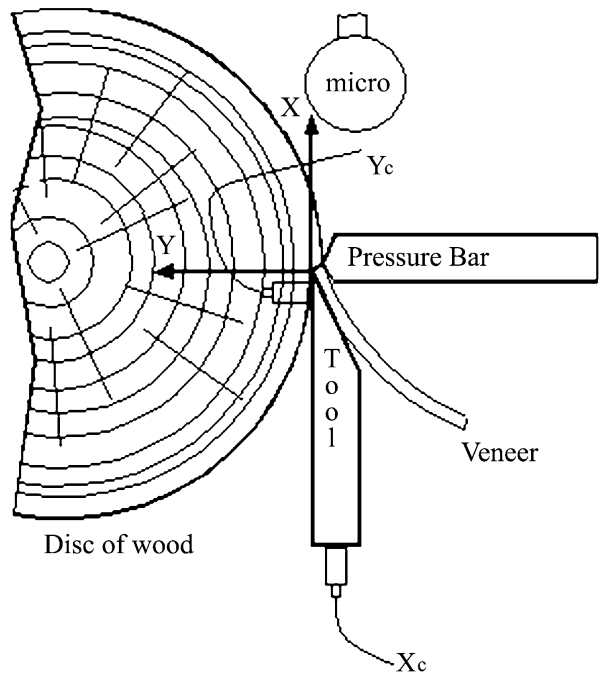

Fig. 3 Experimental setup

Abb. 3 Versuchsanordnung

Some reference papers could be found (Byrne et al. 1995; Dimla 2000) which summarise the main methods used for tool condition monitoring. There is only a very small number of publications which focuses on the wood peeling process. According to Denaud (2006), a survey was conducted to determine what kind of phenomenon operators are able to identify "by hearing". Ten operators, from five different companies representing the French peeling industry were consulted. Each of them was able to detect lathe check occurrence by hearing the sound generated by cutting. This could be in agreement with the results presented by Nagatomi et al. (1999). They found a high correlation between the probability of having a sound pressure level higher than a given threshold and the surface roughness of the veneer. They also suggested that the most important peaks mea- 
sured from the microphone signal could be attributed to lathe check occurrence. Nevertheless, they did not explain how this threshold was chosen.

Denaud et al. (2007) proposed a method to obtain the position of each check along the veneer during the process from acoustic and vibratory temporal data. It requires a local RMS (Root Mean Square) averaging via a peak detection algorithm with no threshold. Results are promising but this approach seems to be more suitable for laboratory measurements. In a first step, operators need simple information to adjust the cutting parameters. Since the lathe checking phenomenon is almost periodic for homogeneous species, "average" lathe check frequency could be a first pertinent indicator to supply a process monitoring system. The possibility of using Power Spectral Density estimation to measure the average lathe check's frequency of the veneer for homogeneous species was introduced by Denaud et al. (2005). Indeed, by comparing the spectrum obtained for a thin beech veneer (almost unchecked) and a thick beech veneer (severely checked), the emergence of a peak corresponding to the veneer average lathe check frequency could be pointed out.

This paper proposes a comparison of different classical signal analysis techniques regarding their ability to measure the average lathe check frequency. Trials were conducted for two homogeneous species (beech and poplar) on the microlathe of LaBoMaP in A\&M ParisTech Cluny (Fig. 2). This apparatus is well adapted to such kind of experiments. Its main characteristics are described in Butaud et al. (1995).

\section{Materials}

\subsection{The microlathe}

A\&M ParisTech microlathe allows for studying the peeling mechanism at reduced scale. The sample is a disk mounted on a gearbox connected to a brushless servo motor. The disk thickness is limited to $30 \mathrm{~mm}$, which has two major advantages. First, it is assumed that the wood disk properties are constant along its width. This configuration also reduces drastic vibrations occurring at the end of the peeling operation which will be considered as perturbations in view of measuring the average lathe check frequency of the veneer. The tool, the pressure bar and their holders are mounted on two independent crows. Both are part of a stiff piezoelectric dynamometrical system (load exerted by the tools could be measured during the geometrical parameters adjustment) which is fixed on a translating carriage.

\subsection{Acquisition chain}

According to the operators' abilities, sensors being compatible with the audible ranges were selected to measure both sound and vibrations during the process (experimental setup sketched in Fig. 3). A capacitor microphone $( \pm 0.25 \mathrm{~dB}$ between $8 \mathrm{~Hz}$ and $12.5 \mathrm{kHz}$ ) was fixed to the carriage in front of the cutting edge of the knife. This system keeps the distance between the assumed sound source (i.e., the cutting area) and the sensor constant in any situation. This position was defined after some preliminary trials to get the finest signal from the cutting area taking into account spatial requirements. Two piezoelectric accelerometers $( \pm 1 \mathrm{~dB}$ between $0.5 \mathrm{~Hz}$ and $17 \mathrm{kHz}$ ) were bolted on the knife to maximise the accuracy of the measure: the first one near the edge of the knife (the sensor mass must be negligible) in the radial direction called $Y c$ and the second one under the knife in the cutting direction called $X c . Y c$ position ensures a very high sensitivity to vibrations generated by the cut, but it requires extra space. Then, a specific larger knife was designed (60 mm instead of $40 \mathrm{~mm}$ generally for the microlathe) nevertheless with a usual bevel angle of $20^{\circ}$.

Sensors were connected to a multi-analyser system (PULSE of Brüel \& Kjær). It is an acquisition and treatment system able to make real-time analysis. The sampling frequency was set to $65536 \mathrm{~Hz}$ to allow treating the signal for frequencies up to $25.6 \mathrm{kHz}$ according to the Shannon criteria and the real filter capabilities. The sampling frequency required for analysis presented in the rest of this paper is much smaller. Nevertheless, those experiments are extracted from a larger experimental plan which needed the full audible range (see Denaud 2006).

\section{Methods}

\subsection{Analysis techniques}

Because lathe checking phenomenon is almost periodic for homogeneous species, spectral representation of the sensors signal appears to be the most natural approach to identify their signature. Classical signal processing tools have been tested: fractional-octave analysis for microphone signal and for each sensor: PSD estimation via periodogram computation, coherence calculation and envelope analysis. The respective benefit of each technique will be discussed in the corresponding analysis parts. Computations were made either directly from Pulse software or from simple routines developed with Labview software.

A complete characterisation of the mechanical behaviour of a device is a long and expensive operation for a company which could only be justified for high added value productions. On the other hand, without the spectral response of the microlathe, the distinction between resonance frequencies (or other phenomena considered as perturbations) and defect signatures could be difficult to establish. 
Table 1 Lathe check frequency measurements for beech and poplar veneers

Abb. 1 Messergebnisse der Rissfrequenz von Buchen- und Pappelfurnieren

\begin{tabular}{ccc||ccc}
\hline \hline $\begin{array}{c}\text { Beech } \\
\text { number of } \\
\text { cracks }\end{array}$ & $\begin{array}{c}\text { length of } \\
\text { measurement } \\
(\mathrm{mm})\end{array}$ & $\begin{array}{c}\text { lathe check } \\
\text { frequency } \\
\text { expected }(\mathrm{Hz})\end{array}$ & $\begin{array}{c}\text { Pumber of } \\
\text { cracks }\end{array}$ & $\begin{array}{c}\text { length of } \\
\text { measurement } \\
(\mathrm{mm})\end{array}$ & $\begin{array}{c}\text { lathe check } \\
\text { frequency } \\
\text { expected }(\mathrm{Hz})\end{array}$ \\
\hline \hline 223 & 644 & 173.1 & 167 & 639 & 130.7 \\
121 & 376 & 160.9 & 139 & 512 & 135.7 \\
82 & 241 & 170.1 & 30 & 115 & 130.4 \\
39 & 118.5 & 164.6 & 65 & 242 & 134.3 \\
37 & 108.5 & 170.5 & 66 & 236 & 139.8 \\
& 313 & 169.3 & 46 & 188 & 122.3 \\
& 106 & 170.2 & 49 & 219 & 111.9 \\
\hline \hline & 230 & 169.0 & 562 & 2151 & 130.6
\end{tabular}

Thibaut (1988) and Décès-Petit (1996) have used PTFE (Polytetrafluoroethylen) to model a "perfect wood" (isotropic). On such a material, the cutting mechanism and the cutting forces are comparable to those observed for wood. Following an analogous reasoning, a PTFE disk was peeled to get a signature of the dynamical behaviour of the microlathe. This approach constitutes a simple and relatively cheap mean to obtain very useful reference signals.

\subsection{Trials}

In a first approach, very favourable cutting conditions for crack formation were employed to make lathe check signature easier to identify (at the same time a more important and more regular phenomenon).

Tests have been performed on a $20 \mathrm{~mm}$ thick disk free from defects for both wood species (beech and poplar). They were sawn and stored under water (ambient temperature) prior to the peeling operation. All the cutting parameters not significantly influencing the lathe check phenomenon were set to their conventional values. No pressure bar was used and the veneer thickness was set to 1 and $3 \mathrm{~mm}$ to obtain two characteristic situations: slightly checked veneers for the thin ones and strongly checked veneers for the thicker ones.

The cutting speed was chosen linearly constant which means that the rotation speed of the motor increased with radius reduction of the disc. In this way, the cutting mechanism and consequently lathe check formation are stable. For a constant rotation speed of the bolt, the phenomenon could no longer be considered to be periodic in the time domain. Treatments of the data could be achieved by a constant time window. The cutting speed $\left(V_{c}\right)$ was chosen equal to $0.5 \mathrm{~m} / \mathrm{s}$. This is lower than the commonly used speed in industry but the expected frequency for lathe check phenomenon would not be too close to a main mechanical mode of the device. Moreover, even if the lathe check phenomenon could be disturbed by this low cutting speed, this will not affect the aim of this work: the identification of the average lathe check frequency on signals.

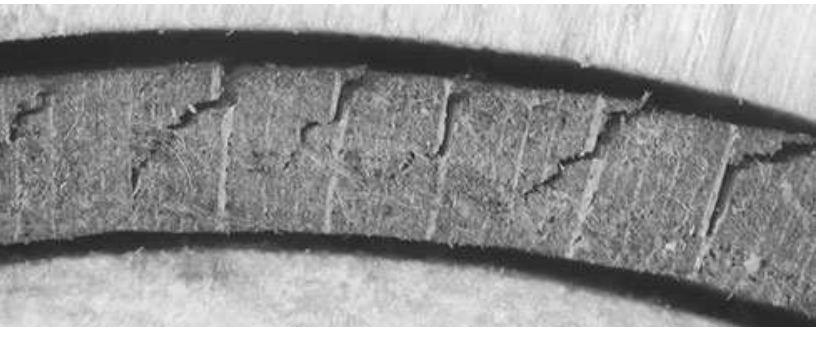

Fig. 4 Lateral view of checked beech veneer under the microscope Abb. 4 Mikroskopische Aufnahme von gerissenem Buchenfurnier. Seitenansicht

\subsection{Lathe check measurement}

The mean lathe check frequency ( $\left.f_{\text {check }}\right)$ of the veneer is calculated with (1).

$f_{\text {check }}=\frac{n}{L} V_{c}$

Thin beech veneer ( $1 \mathrm{~mm}$ thick) was slightly and partially cracked. For the same thickness, poplar veneer was free from any cracks. As it was expected, it would be considered as veneer with no crack. For thick veneers, Table 1 presents the achieved measurements. Lathe check phenomenon is not perfectly periodic which is in agreement with the results presented by Palubicki et al. (2010) or Thibaut (1988) for similar samples. Indeed, wood is a biological material including different levels of heterogeneity. Small variations of its local properties affect its toughness. Figure 4 shows the cross-section of a $3 \mathrm{~mm}$ thick beech veneer which is strongly checked. The presence of wood rays clearly modifies the way of crack propagation. Poplar ligneous rays could not play the same role because they are uniseriate (only one row of cells). Nevertheless, a comparable variability in the average lathe check frequency was observed (Table 1). The eccentric between the geometric centre of the disk and the pith is another reason for a variation of the average lathe check interval observed even for homogeneous species. This geometry alternatively favours or limits lathe check growth during a peeling turn as described by Takano and Fujimoto 
(1999). To take this into account when measuring the average lathe check frequency, one turn should at least be considered. The last peeling turns measure $863 \mathrm{~mm}$ and $562 \mathrm{~mm}$ for beech disk and poplar disk, respectively.

To conclude, even if the causes of variation in the average lathe check frequency are numerous and difficult to distinguish, an average value obtained from more than $2000 \mathrm{~mm}$ of veneer could be considered as representative for this study.

\section{Average lathe check frequency identification}

\subsection{PSD estimation}

To normalise the measurement with respect to the analysis bandwidth, PSD was overridden. PSD were estimated by the periodogram method: autospectrum using Discrete Fourier Transform of signals thanks to (2).

$S_{X X}(f)=E\left[\hat{X}^{*}(f) \cdot \hat{X}(f)\right]$

$*$ indicates complex conjugation.

The individual estimates of $X(f)$ in (2) are defined by (3) and computed at the discrete frequencies $f$ as defined by (4) (formulas from B\&K Technical Review $n^{\circ} 1,1984$ ).

$\hat{X}_{i}(f)=\int_{T} x(t) e^{-2 j \pi f t} d t$

$f=k . \Delta f=k .1 / T$

Some computation parameters were settled after several iterations to improve the readability of the spectrum:

- Signal duration: 2 seconds to get more than one turn of the disk within the same time (note that it is never the first one. Indeed, during this turn, thickness varies from zero to the nominal one.) and a stable spectrum taking into account averaging parameters.

- Hanning weighting: well suitable for rotary devices control, it prevents from discontinuities introduced by uniform windows according to $\mathrm{B} \& \mathrm{~K}$ Technical Review $\mathrm{n}^{\circ} 3$ (1987). Moreover, associated to both a high overlap (75\% at least) and a linear averaging, this weighting tends to be similar to a uniform one without its drawbacks.

- The spectral domain: from 0 to $3.2 \mathrm{kHz}$. This band is conservatively rated according to the experimental settings (lathe check frequency obtained from veneer characterisation).

- $T$ : Time window computation of $125 \mathrm{~ms}(N$, number of lines fixed to 400). The spectral resolution $(8 \mathrm{~Hz})$ obtained is suitable to detect not perfectly periodic phenomena as lathe check. At the same time, the relatively small size of this window allows to achieve a high number of calculations on recorded signals.

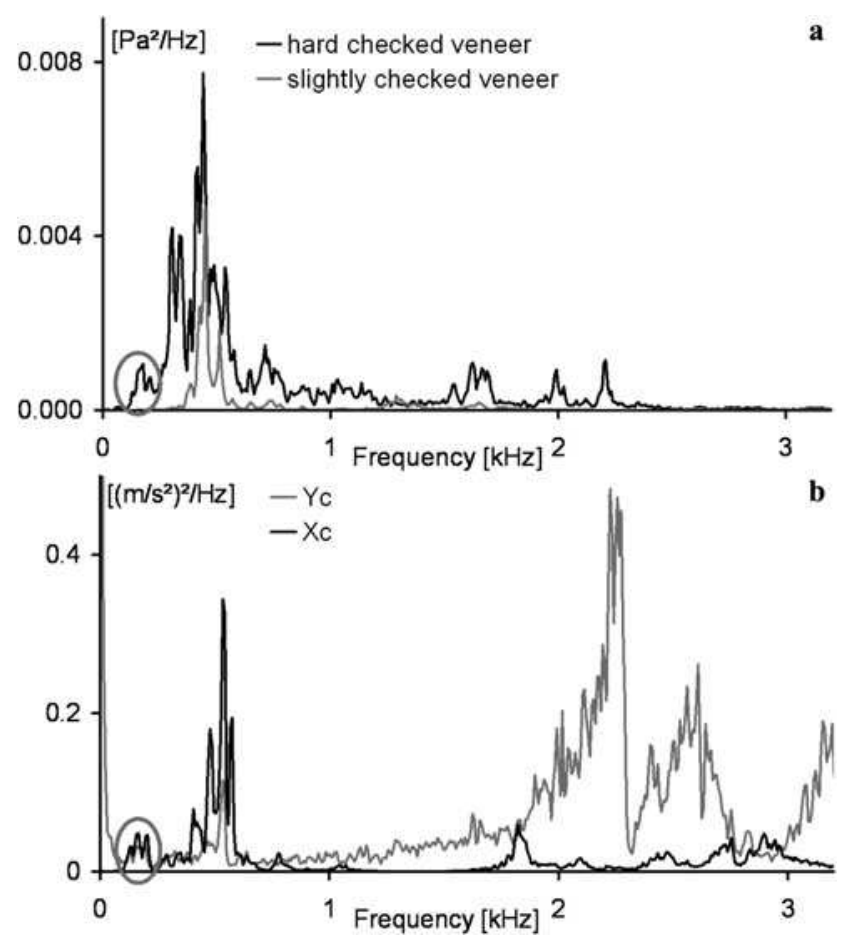

Fig. 5 Power spectral density estimation from: (a) microphone signal for strongly checked beech ( $3 \mathrm{~mm}$ thick) veneer and softly checked beech veneer (1 mm thick), (b) accelerometers $X c$ and $Y c$ for strongly checked beech veneer

Abb. 5 Spektrale Leistungsdichte bestimmt mittels: (a) eines Mikrophonsignals bei stark gerissenem $3 \mathrm{~mm}$ dickem sowie leicht gerissenem $1 \mathrm{~mm}$ dickem Buchenfurnier, (b) Beschleunigungsaufnehmern $X c$ und $Y c$ bei stark gerissenem Buchenfurnier

- Linear averaging: Each spectrum is the result of at least 250 calculations.

Average lathe check frequency of strongly checked beech veneer is close to $169 \mathrm{~Hz}$ according to the results presented in Table 1. Each concerned spectrum (both in Fig. 5(b) and the first one in Fig. 5(a)) shows a significant peak, or more precisely a band (grey circled), corresponding to this range of frequencies (between 136 and $208 \mathrm{~Hz}$ with a maximum for $168 \mathrm{~Hz} \pm 4 \mathrm{~Hz}$ ).

Moreover, PSD obtained for not checked veneers do not present any peaks in this range of frequencies. As a proof, simply observe the spectrum estimated from the microphone signal shown in Fig. 5(a) (grey curve in the grey circled area). It confirms the possibility of using PSD of accelerometers or microphone signals raised by Denaud et al. (2005) to detect lathe check occurrence via their average frequency. As for the phenomenon itself, this kind of signature is a combination of a periodic and a random non stationary component.

However, the identification of peaks attributed to checks occurrence is not trivial without getting the results from veneer measurements. This requires a long and expensive modal characterisation of the lathe to discard signatures 
Fig. $61 / 12$-octave band power spectrum from microphone signals for strongly checked poplar veneer

Abb. 6 1/12 Oktavband Leistungsspektrum eines Mikrophonsignals bei stark gerissenem Buchenfurnier
[dB/20.0u Pa]

Autospectrum (micro)

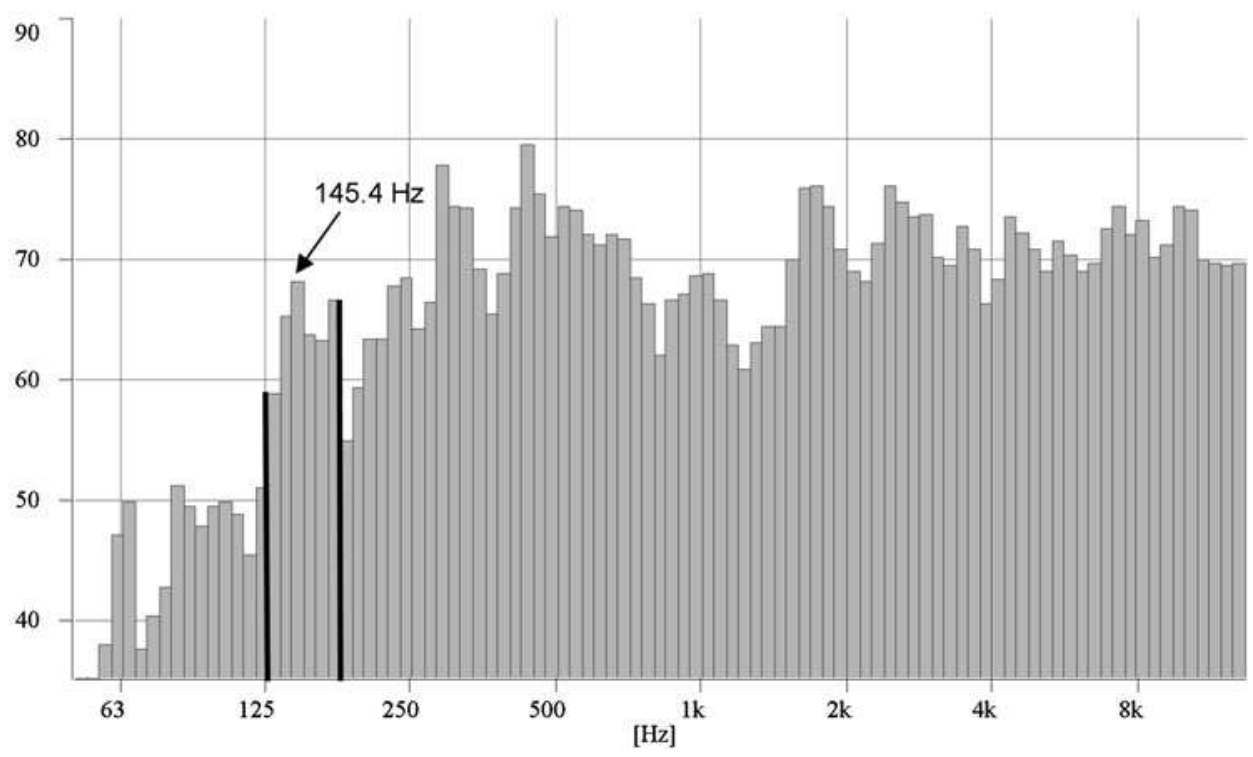

of its mechanical behaviour. This was realized by Denaud (2006) for the microlathe. The highest peak $(576 \mathrm{~Hz})$ close to the lathe check frequency signature was identified as one of the first modes of the system (tool fixed on its tool holder on the device). The other dominant peak of frequency could be attributed to the mechanical behaviour of the device. Getting a comparison signal (see Fig. 5a) could be helpful for operators. Nevertheless, a highly simple indicator is required to fit with industrial constrains.

\subsection{Octave Band Analysis}

It is usually assumed that the human hearing could correctly be modelled by using a logarithmic scale. So, Octave Band Analysis which could present a logarithmic scale in both frequency and level has already been used for both psychoacoustic applications as found in Zwicker et al. (1999), or for more similar applications as by Iskra and Tanaka (2005). The latter authors found a linear, positive and significant correlation ( $r=0.981$ for 13 samples) between the sound intensity obtained from third octave band analysis $(4 \mathrm{kHz}$ centred band) and the surface roughness during routing for different grain angles of a wood piece.

Figure 6 shows the 1/12-octave band power spectrum computed from the microphone signal for strongly checked poplar ( $3 \mathrm{~mm}$ thick - exponentially averaged from $1 \mathrm{~s}$ signal, time constant of $0.5 \mathrm{~s}$, without any weighting). In accordance with the results summarised in Table 1, the band limited by black lines (central frequency from 129.6 to $172.8 \mathrm{~Hz}$ ) corresponds to the signature of the lathe checks. This confirms that the phenomenon studied is not perfectly periodic even for homogeneous species. The maximum raise $68 \mathrm{~dB}$ for $145.4 \mathrm{~Hz}$ central frequency band should be compared to $130.9 \mathrm{~Hz}$ obtained from the veneer. This small difference could be attributed both to the spectral resolution and the tracking uncertainty of the cutting speed which could rise $9 \%$ for such cutting conditions (essentially depending on the radius of the disk as well as on the reference input of the cutting speed).

Even if a comparable experiment for a thin and not checked poplar veneer gives a level of at least $15 \mathrm{~dB}$ lower for $145.4 \mathrm{~Hz}$ central frequency band, it is difficult to identify lathe check signature without knowing its location before. Like PSD computation, this approach is promising but not completely satisfying.

\subsection{Coherence estimation}

The coherence function is a simple and normalised indicator usually devoted to characterise the validity of a transfer function computation. Its formulation for two signals $x(t)$ and $y(t)$ could be expressed by (5) where $S_{x x}(f)$ and $S_{x y}(f)$ represent the autospectrum, i.e., PSD, of $x(t)$ signal and the interspectrum of both signals, respectively.

$\Gamma_{x y}^{2}(f)=\frac{\left|S_{x y}(f)\right|^{2}}{S_{x x}(f) S_{y y}(f)}$

This function is rarely used to monitor cutting processes but an example can be found in $\mathrm{Li}$ et al. (1997). They used two accelerometers perpendicularly glued to the tool holder for turning experiments. They obtained a coherence function almost equal to 1 for the chatter vibration. Figure 7(a) and (b) show coherence functions (computation parameters are defined in Sect. 4.1 and coherence functions are linearly averaged on the duration of the signals) for strongly checked beech and poplar veneer, respectively, between each pair of sensors. In Fig. 7(a), 

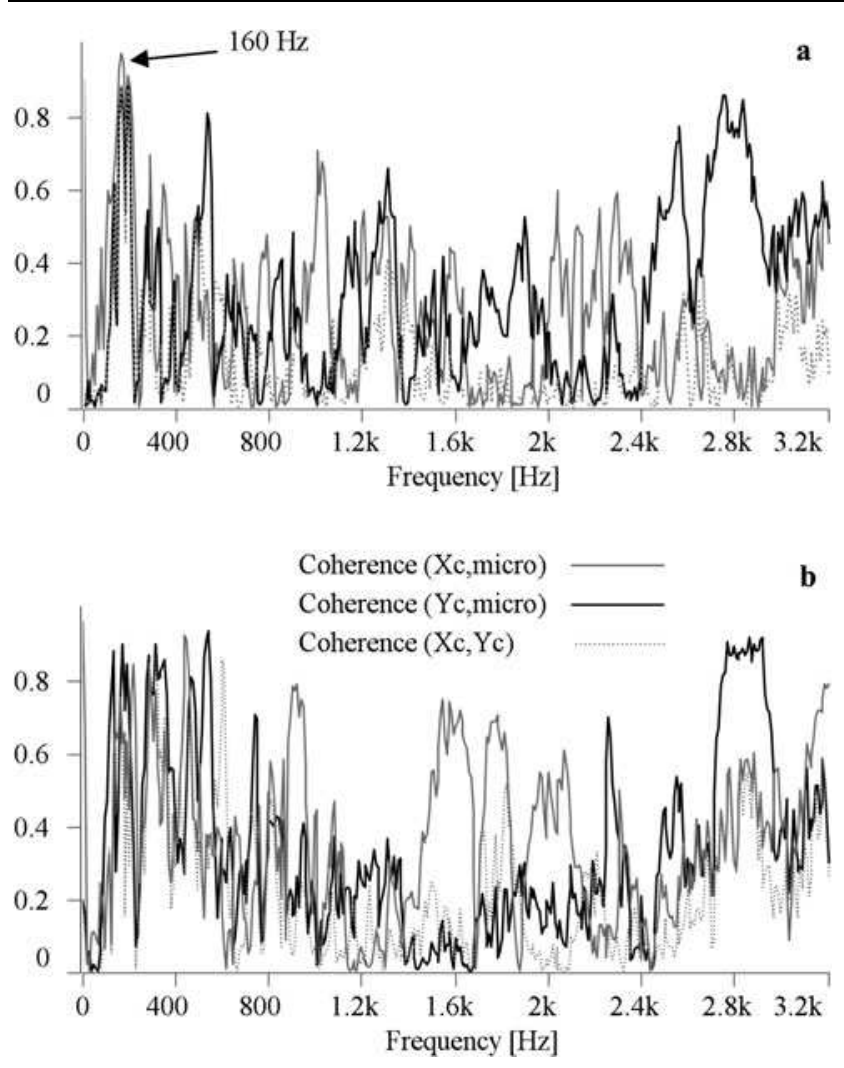

Fig. 7 Coherence function for both accelerometers and the microphone for: (a) strongly checked beech veneer, (b) strongly checked poplar veneer

Abb. 7 Kohärenzfunktionen für die Beschleunigungsaufnehmer und das Mikrophon bei (a) stark gerissenem Buchenfurnier, (b) stark gerissenem Pappelfurnier

it is easy to identify a band of frequency (from 104 to $208 \mathrm{~Hz}( \pm 4 \mathrm{~Hz}))$ containing the average lathe check frequency of beech veneer measured at $169 \mathrm{~Hz}$. Although its quite large width suggests a high sensitivity to the modal signature of the device, the most promising couple is not decidedly the accelerometer $X c$ (cutting direction) and the microphone. Its coherence function exceeds 0.9 for $160 \mathrm{~Hz}$ which constitutes the maximum in the considered range of frequency. At bottom, this coherence function should be able to eliminate from the spectrum at the same time lathe's natural frequencies, and acoustical perturbations are included in what could be called the back ground noise. If this thread of reasoning could be followed for the beech experiment, the coherence functions obtained from beech peeling are not simply usable. This underlines the dependence of this indicator on the signal energy, which is in the case of beech almost twice the one of poplar in the same conditions (RMS of $X c$ signal computed on one turn of the lathe is $68.183 \mathrm{~m} / \mathrm{s}^{2}$ for poplar and $107.180 \mathrm{~m} / \mathrm{s}^{2}$ for beech). Although this way has seemed to be promising, its poor suitability for low density woods makes one suspicious of its efficiency for softly checked veneers.

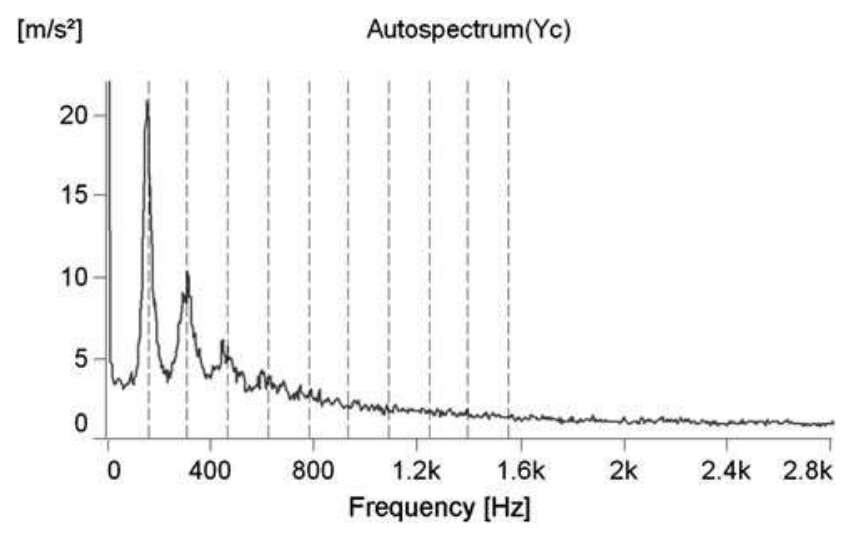

Fig. 8 Envelope analysis of $Y c$ accelerometer signal for strongly checked poplar veneer

Abb. 8 Hüllkurvenanalyse des Beschleunigungsaufnehmersignals $Y c$ bei stark gerissenem Pappelfurnier

\subsection{Envelope analysis}

Time domain observations suggest that amplitude modulations of sensor signals are probably due to both the disk rotation and the lathe check phenomenon only if it is well established. Envelope analysis allows extracting the modulating component of the signal (amplitude of demodulation). Figure 8 shows the envelope analysis of the signal of $Y c$ accelerometer recorded during peeling of a strongly checked poplar veneer. Computation parameters were selected by several iterations to improve the spectrum readability (envelope analysis with a central frequency of $12.8 \mathrm{kHz}$ for a $25.6 \mathrm{kHz}$ total band analysis: computation for $1 \mathrm{~s}$ signal, $T=250 \mathrm{~ms}, N=3200$, Hanning weighting, overlap $=95 \%$, linear averaging with 250 averages).

The primary modulating frequency could be recognised as the average lathe check one: the fundamental could be identified for a frequency of $152 \mathrm{~Hz}( \pm 4 \mathrm{~Hz})$ and a few following harmonics are pointed out (grey doted). Once again this frequency is slightly overestimated regarding direct measurements. This could be attributed to the reasons previously mentioned (see Sect. 4.2). Notice that the inescapable unbalance, mostly due to the intrinsic heterogeneity of the wood disk around its periphery, is characterised by the highest peak in Fig. 8 (visible on the spectrum for the first band of frequency: $0-8 \mathrm{~Hz}$ ).

Unfortunately, if the $X c$ accelerometer signal still shows a clear peak for $152 \mathrm{~Hz}$, the microphone envelope spectrum is largely disturbed by other modulation frequencies probably attributed to the brushless motor of the lathe. Indeed, to keep a linear cutting speed constant, it has to accelerate its rotation speed whilst the radius of the disk decreases.

Nevertheless, this simple approach is the most promising one. It is possible to identify the occurrence of deep and almost regular checks without knowing before where to look for on the spectrum issued from accelerometer signals. 


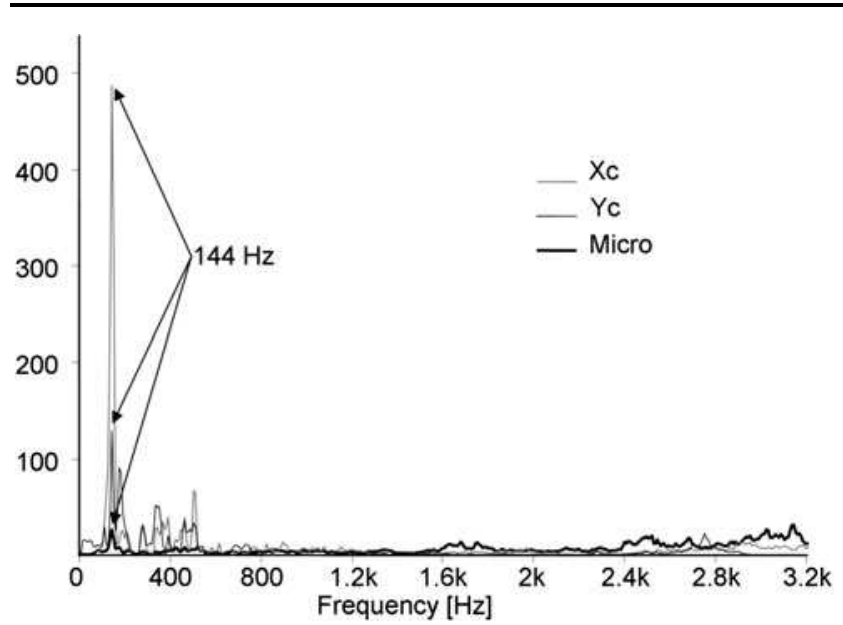

Fig. 9 PSD ratio (strongly checked poplar veneer/PTFE)

Abb. 9 Spektrales Leistungsdichteverhältnis zwischen stark gerissenem Pappelfurnier und Polytetrafluoroethylen

\subsection{PSD ratio}

As it was shown before, the poor readability of both PSD estimation and octave band analysis is mostly due to the mechanical behaviour of the device. So, a disk of PTFE was peeled (the thickness was fixed to $1 \mathrm{~mm}$ which is adequate for this application and relatively economic in terms of material consumption) to play the role of a reference signal. Then, by computation of the PSD ratio between magnitude spectrums obtained for wood and PTFE peeling, respectively, the resonance frequencies of the device should be at least partially removed from the spectrums. Figure 9 presents PSD estimation ratio of each sensor signal obtained for hard checked poplar veneer peeling. The computation settings are rigorously the same as the ones presented in the PSD estimation part.

It is noticeable that having favoured PSD estimation simplifies the calculation procedure because the energy per $\mathrm{Hz}$ is independent of bandwidth analysis. This makes changes in the computation parameters of the current cutting experiment possible without using another reference signal.

The "signal to noise" ratio is greatly improved. The peak magnitude ( $f=144 \mathrm{~Hz}$ for each sensor) of the band due to lathe check phenomenon is the maximum for all sensors in this range of frequency. It starts from 27 for the microphone to reach a little bit less than 500 for $X c$ accelerometers. The same procedure was applied for hard checked beech veneers and quite similar results were obtained: a maximum of 120 for $168 \mathrm{~Hz}$ for the microphone and for $X c$ accelerometer a maximum of 181 for a frequency equal to $176 \mathrm{~Hz}$. This is undoubtedly the most promising signal processing method. A very simple algorithm (maximum or peak detection) could be built to automatically detect the lathe check signature in this range of frequencies.

As regards the industrial context, the cost of a bolt of a few meters long of PTFE could be crippling. To avoid this

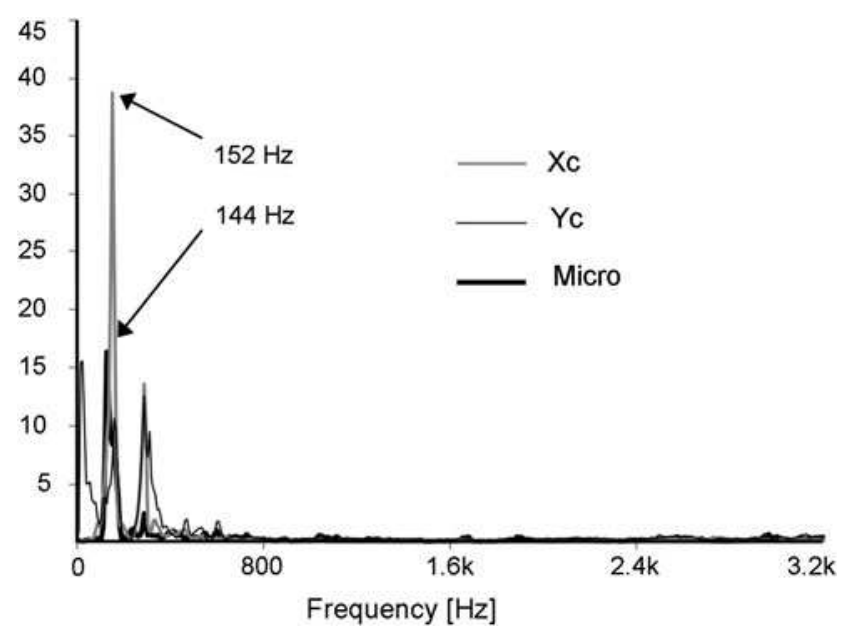

Fig. 10 PSD ratio (strongly checked poplar veneer/poplar veneer peeled with high pressure rate)

Abb. 10 Spektrales Leistungsdichteverhältnis zwischen stark gerissenem Pappelfurnier und bei hohem Pressdruck geschältem Pappelfurnier

difficulty, a cheaper solution was contrived to get a reference signal. As detailed in the introduction, the use of a pressure bar limits lathe check formation but generates thickness variations of the veneer. Even if the veneer produced using a very high pressure rate of the pressure bar would not be conforming, the recorded signal could constitute a good reference considering lathe checking. A peeling operation of a poplar veneer was recorded using the same conditions as detailed in the trial part except for the pressure rate (fixed to $25 \%$ of the veneer thickness when usual settings are between 10 and $15 \%$ of the veneer thickness). Figure 10 shows PSD ratio obtained for strongly checked poplar veneer with this last record used as a reference. Although the peak is not like the one seen in Fig. 9, the readability of the spectrums is still excellent, especially for $X c$ and microphone spectrums. $Y c$ signal is very sensitive to the compression exerted by the pressure bar. The spectrum presents three almost equidistant peaks (distance of $140 \mathrm{~Hz}$ ) which seem to be the signature of an amplitude modulation due to the average lathe check frequency. Finally, PSD ratio readability is not significantly altered since an automatic detection (local maximum, algorithm of peak detection, etc.) is still easy to perform.

\section{Conclusion}

This work presents a comparative study of conventional simple processing tools to measure on-line the average lathe check frequency of homogeneous wood veneers. Two main results are pointed out. Firstly, the envelope analysis of signals provided by accelerometers fixed on the knife could be a good mean to get this information without using any reference signal. Secondly, an original approach is proposed 
based on PSD ratio estimation. Further analyses have to be conducted to characterise the PSD ratio sensitivity to usual cutting parameters. In particular with a view to develop an on-line control of the process, the pressure rate influence has to be investigated because it is still one of the hardest compromises that an operator has to find. Moreover, the role of the pressure rate on the check average distance or depth has never been carefully established because of a lack of efficient and quite fast measurement means even if recent attempts could be found (Tomppo et al. 2009). All these developments are now possible thanks to a new powerful apparatus called SMOF which has been developed by Palubicki et al. (2010).

\section{References}

Butaud J-C, Deces-Petit C, Marchal R (1995) An experimental device for the study of wood cutting mechanisms: the microlathe. In: Poster session proceedings of the 12th int wood mach semi, October 2-4, 1995, Kyoto, Japan, pp 479-485

Brüel \& Kjaer (1984) Technical review $n^{\circ} 1$ : dual channel FFT analysis part I, ISNN 007-2621, 60 pp

Brüel \& Kjaer (1987) Technical review n³: windows to FFT analysis part I ISNN 007-2621, 44 pp

Byrne G, Dornfeld D, Inasaki I, Ketteler G, König W, Teti R (1995) Tool condition monitoring (TCM) - the status of research and industrial application. CIRP Ann Manuf Technol, 44(2):541-567

Décès-Petit C (1996) Study of transitory phases during wood peeling (in French). PhD thesis, ENSAM Cluny, $120 \mathrm{pp}$

Denaud L-E, Bleron L, Ratle A, Marchal R (2005) Vibro-acoustic analysis of wood peeling process: temporal and spectral analysis. In: Proceedings of the 17th int wood mach semi, Rosenheim, Germany, pp 55-65

Denaud L-E (2006) Vibration and acoustic analyses of peeling (in French). PhD thesis, ENSAM Cluny, France

Denaud L-E, Bleron L, Ratle A, Marchal R (2007) Online control of wood peeling process: acoustical and vibratory measurements of lathe checks frequency. Ann For Sci 64:569-575

DeVallance DB, Funck JW, Reeb JE (2007) Douglas-Fir plywood gluebond quality as influenced by veneer roughness, lathe checks, and annual ring characteristics. For Prod J 57(1/2):21-28

Dimla DE Sr (2000) Sensor signals for tool-wear monitoring in metal cutting operations - a review of methods. Int J Mach Tools Manuf 40:1073-1098
Iskra P, Tanaka C (2005) The influence of wood fiber direction, feed rate, and cutting width on sound intensity during routing. Holz Roh- Werkst 63(3):167-172

Leney L (1960a) Mechanism of veneer formation at the cellular level. Research bulletin no 744, University of Missouri, College of Agriculture, Agricultural Experiment Station, $111 \mathrm{pp}$

Leney L (1960b) A photographic study of veneer formation. For Prod J 10(3):133-139

Li XQ, Wong YS, Nee AYC (1997) Tool wear and chatter detection using the coherence function of two crossed accelerations. Int $\mathbf{J}$ Mach Tools Manuf 37:425-435

Lutz JF (1974) Techniques for peeling process, slicing, drying veneer, FPL, Forest Ser. U.S.D.A., 228 pp

Marchal R, Dai C, Wang B (2000) Online control of wood peeling process using acoustic and vibration: first results (in French). In: 6th symposium PPF "Maîtrise globale du procédé d'enlèvement de matière et des techniques associées", ENSAM Metz, France, pp 34-44

Marchal R, Mothe F, Denaud L-E, Thibaut B, Bleron L (2009) Cutting forces in wood machining - basics and applications in industrial processes. Holzforschung 63:157-167

Nagatomi K, Yoshida K, Banshoya K, Murase Y (1999) Relation between veneer quality and peeling sound in the peeling of Sugi. In: Proceedings of the 13th int wood mach semi, June 17-20, Vancouver, Canada, pp 681-690

Ohya S, Kitayama S, Kawaguchi M (1989) The effect of veneer quality on the bending strength of laminated wood. Mokuzai Gakkaishi 35(10):905-911

Palubicki B, Marchal R, Butaud J-C, Denaud L-E, Bleron L, Collet R, Kowaluk G (2010) A method of lathe checks measurement; SMOF device and its software. Eur J Wood Prod 68:151-159

Takano T, Fujimoto K (1999) Development of surface defects in softwood Veneer peeling. In: Proceedings of the 14th int wood mach semi, France, pp 417-424

Thibaut B (1988) Wood cutting process by peeling (in French). PhD thesis, Université des Sciences et Techniques du Languedoc, $386 \mathrm{pp}$

Thibaut B, Beauchêne J (2004) Links between wood machining phenomena and wood mechanical properties: the case of $0^{\circ} / 90^{\circ}$ orthogonal cutting of green wood. In: Proceedings of the 2 nd int symp on wood mach. Vienna, Austria, pp 149-160

Tomppo L, Tiitta M, Lappalainen R (2009) Ultrasound evaluation of lathe check depth in birch veneer. Eur J Wood Prod 67:27-35

Zwicker E, Fastl H, Frater H (1999) Psychoacoustics facts and models, 2nd edn. Springer, Berlin 